\title{
WYKAZ PUBLIKACJI \\ PROF. DR HAB. DOBROCHNY JANKOWSKIEJ \\ ZA LATA 1967-2014
}

\author{
LIST OF PUBLICATIONS BY ASSOCIATE \\ PROFESSOR DOBROCHNA JANKOWSKA 1967-2014
}

\section{7}

1. Odkrycia. Materiały Zachodniopomorskie, 11(1965), s. 889-935.

\section{8}

2. [rec.] Edith Hoffmann, Die Kultur der Bandkeramik in Sachsen, cz. I, „Die Keramik”, Berlin 1963. Materiały Zachodniopomorskie, 12(1966), s. 758-760.

3. Sprawozdanie z działalności Muzeum w Szczecinku w 1966 roku. Materiały Zachodniopomorskie, 12 (1966), s. 830-831.

4. Szczecinek. Informator Archeologiczny, Badania 1967, s. 88-89.

\section{9}

5. Cmentarzysko ludności kultury pomorskiej w Szczecinku, stanowisko 5. W: F.J. Lachowicz (red.), Sprawozdania z badań archeologicznych prowadzonych na terenie województwa koszalińskiego w latach 1967-1968, Koszalin: Prezydium Wojewódzkiej Rady Narodowej, s. 65-74.

6. [współautor: F.J. Lachowicz] Jabłończ Wielki, pow. Bytów. Stanowisko 1. Informator Archeologiczny, Badania 1968, s. 244-246.

\section{0}

7. [współautor: F.J. Lachowicz] Łupawa, pow. Słupsk. Stanowisko 8. Informator Archeologiczny, Badania 1969, s. 83-85.

8. [współautor: F.J. Lachowicz] Porzecze, pow. Sławno. Stanowisko 2. Informator Archeologiczny, Badania 1969, s. 130-131.

9. [współautor: R. Kamiński] Porzecze, pow. Sławno. Stanowisko 3. Informator Archeologiczny, Badania 1969, s. 164. 


\section{1}

10. Wczesnośredniowieczne osady typu wiejskiego na Nizinie Wielkopolskiej. Studia i Materiały do Dziejów Wielkopolski i Pomorza, 10/2, s. 11-42.

\section{2}

11. Archeologiczna praktyka terenowa i jej funkcje dydaktyczno-wychowawcze. Neodidagmata, 4, s. 189-196.

12. [współautor: F.J. Lachowicz] Łupawa, pow. Słupsk. Stanowisko 8. Informator Archeologiczny, Badania 1971, s. 58-59, 318-319.

13. [współautorzy: A. Kośko, F.J. Lachowicz] Łupawa, pow. Słupsk. Stanowisko 15. Informator Archeologiczny, Badania 1971, s. 29-30.

14. Poganice, stanowisko 4. Informator Archeologiczny, Badania 1971, s. 34-35.

\section{3}

15. [współautor: A. Kośko] Łupawa, pow. Słupsk. Stanowisko 15. Informator Archeologiczny, Badania 1972, s. 30-31.

16. Poganice, stanowisko 4. Informator Archeologiczny, Badania 1972, s. 36-37.

17. Sprawozdanie z prac wykopaliskowych na osadzie kultury pucharów lejkowatych w Poganicach, pow. Słupsk, stanowisko 4, w 1971 roku. Koszalińskie Zeszyty Muzealne, 2(1972), s. 229-236.

\section{4}

18. [współautor: M. Cwetsch] Łupawa, pow. Słupsk. Stanowisko 15. Informator Archeologiczny, Badania 1973, s. 28-29.

19. Łupawa, stanowisko 18. Informator Archeologiczny, Badania 1973, s. 29-30.

20. O metodzie badania grobowców megalitycznych. W: F.J. Lachowicz (red.), Studia Archaeologica Pomeranica, Koszalin: Muzeum Archeologiczno-Historyczne w Koszalinie, s. 79-91.

21. Poganice, stanowisko 4. Informator Archeologiczny, Badania 1973, s. 35-36.

22. [współautor: A. Kośko] Sprawozdanie z badań nad osadnictwem kultury pucharów lejkowatych na Pomorzu Środkowym w 1972 r. Koszalińskie Zeszyty Muzealne, 3(1973), s. 30-46.

\section{5}

23. Cmentarzysko kultury pucharów lejkowatych w Łupawie, pow. Słupsk (stanowisko 15). Sprawozdania Archeologiczne, 27, s. 27-42.

24. Łupawa, stanowisko 18. Informator Archeologiczny, Badania 1974, s. 38-39.

25. Poganice, stanowisko 4. Informator Archeologiczny, Badania 1974, s. 42-43.

26. Sprawozdanie z prac wykopaliskowych na stanowisku $4 \mathrm{w}$ Poganicach, pow. Słupsk, w 1973 roku. Koszalińskie Zeszyty Muzealne, 4(1974), s. 3-12. 


\section{6}

27. Die kulturellen Zusammenhänge zwischen der Trichterbecherkultur und Kugelamphorenkultur im Gebiet von Pommern. Zeitschrift für Archäologie, 10/1, s. 21-22.

28. Łupawa, stanowisko 18. Informator Archeologiczny, Badania 1975, s. 38.

29. Poganice, gm. Łupawa, woj. słupskie. Informator Archeologiczny, Badania 1975, s. 43.

\section{7}

30. Relacje między kulturą pucharów lejkowatych a amfor kulistych na Pomorzu. Pomorania Antiqua, 7, s. 9-15.

31. [współautor: A. Weber] Łupawa, stanowisko 18. Informator Archeologiczny, Badania 1976, s. 38-39.

\section{8}

32. Łupawa, stanowisko 18. Informator Archeologiczny, Badania 1977, s. 39.

33. Obrządek pogrzebowy grupy łupawskiej kultury pucharów lejowatych. Sprawozdania z Posiedzeń Poznańskiego Towarzystwa Przyjaciół Nauk, 95.

\section{9}

34. Łupawa, stanowisko 2. Informator Archeologiczny, Badania 1978, s. 32.

35. Poganice, stanowisko 4. Informator Archeologiczny, Badania 1978, s. 37-38.

36. Żochowo, gm. Potęgowo, stanowisko 21, Informator Archeologiczny, Badania 1978, s. 214-215.

37. [współautor: R. Madaj] Wojnowice, stanowisko 2. Informator Archeologiczny, Badania 1978, s. 210-211.

38. [współautorzy: A. Kośko, K. Siuchniński, H. Quitta, G. Kohl] Untersuchungen zur Chronologie der neolithischen Kulturen im Polnischen Tiefland. Zeitschrift für Archäologie, 13/2, s. 219-240.

\section{0}

39. Kultura pucharów lejkowatych na Pomorzu Środkowym. Grupa łupawska, Poznań: Wydawnictwo Naukowe Uniwersytetu im. Adama Mickiewicza.

40. Łupawa, stanowisko 2. Informator Archeologiczny, Badania 1979, s. 39.

41. Wojnowice, stanowisko 2. Informator Archeologiczny, Badania 1979, s. 197-198.

42. Zabytek sztuki romańskiej z Wojnowic. Slavia Antiqua, 26(1979), s. 335-339.

43. Żochowo, gmina Potęgowo, stanowisko 21. Informator Archeologiczny, Badania 1979, s. 202.

44. [rec.] Vladmir Podborský, Eliška Kazdová, Pavel Koštuřik, Zdeněk Weber, Numerický kód moravské malované keramiký. Problémy deskripce v archeologii, Brno 1977. Przegląd Archeologiczny, 27, s. 197-200. 


\section{1}

45. Bolków, stanowisko 1. Informator Archeologiczny, Badania 1980, s. 9.

46. Kultura pucharów lejkowatych na Pomorzu Środkowym (grupa łupawska) ze szczególnym uwzględnieniem jej obrządku pogrzebowego. W: T. Wiślański (red.), Kultura pucharów lejkowatych w Polsce (studia i materiaty), Poznań: PAN Oddział w Poznaniu i Leszczyńskie Towarzystwo Kulturalne, s. 119-135.

47. Łupawa, gm. Potęgowo, woj. słupskie. Stanowisko 2. Informator Archeologiczny, Badania 1980, s. 38-39.

48. Wojnowice, stanowisko 2. Informator Archeologiczny, Badania 1980, s. 38-39.

49. Wspomnienie o Kazimierzu Siuchnińskim. Koszalińskie Zeszyty Muzealne, 11, s. $129-131$.

\section{2}

50. Bolków, stanowisko 1. Informator Archeologiczny, Badania 1981, s. 9-10.

51. [współautor: J. Wierzbicki] Łupawa, gm. Potęgowo, woj. słupskie. Stanowisko 2 i 2a. Informator Archeologiczny, Badania 1981, s. 45-46.

\section{3}

52. Kultury pucharów lejkowatych i amfor kulistych na Pomorzu. W: T. Malinowski (red.), Problemy epoki kamienia na Pomorzu, Słupsk: Wyższa Szkoła Pedagogiczna i Muzeum Pomorza Środkowego, s. 147-166.

53. Łupawa, stanowisko 27. Informator Archeologiczny, Badania 1982, s. 43.

\section{4}

54. Bolków, stanowisko 1. Informator Archeologiczny, Badania 1983, s. 8.

55. Łupawa, stanowisko 27. Informator Archeologiczny, Badania 1983, s. 39.

56. Z badań nad najstarszym osadnictwem w rejonie dolnej Odry. Materiaty Zachodniopomorskie, 26(1980), s. 19-38.

\section{5}

57. Bolków, stanowisko 1. Informator Archeologiczny, Badania 1984, s. 8.

58. Osadnictwo w Niecce Jezior Bnińskich w epoce kamienia. W: J. Żak, J. Fogel (red.), Materiaty do badań nad osadnictwem bnińskim. Mikroregion bniński, Poznań: Wydawnictwo Naukowe Uniwersytetu im. Adama Mickiewicza, s. 21-34. 59. Poganice, stanowisko 4. Informator Archeologiczny, Badania 1984, s. 31-32.

60. Stan badań nad kulturą ceramiki sznurowej na Pomorzu. Folia Praehistorica Posnaniensia, 1 (1984), s. 63-72. 


\section{6}

61. Bolków, gm. Police, woj. szczecińskie. Stanowisko 1. Informator Archeologiczny, Badania 1985, s. 7-8.

62. Funnel Beaker and Globular Amphorae Cultures in Pomerania. W: T. Malinowski (red.), Problems of the Stone Age in Pomerania, Warszawa: Wydawnictwa Uniwersytetu Warszawskiego, s. 163-185.

63. Materiały neolityczne. W: T. Malinowski (red.), Źródła archeologiczne i antropologiczne do dziejów Rowokołu, Słupsk: Wyższa Szkoła Pedagogiczna w Słupsku, s. 107-110.

64. [współautor: J. Wierzbicki] Poganice, gm. Potęgowo, woj. słupskie. Stanowisko 4. Informator Archeologiczny, Badania 1985, s. 29.

\section{7}

65. [współautor: J. Wierzbicki] Poganice, gm. Potęgowo, woj. słupskie. Stanowisko 4. Informator Archeologiczny, Badania 1986, s. 31.

\section{8}

66. On the question of contacts between Pomerania and the West Baltic zone during the Stone Age. Folia Praehistorica Posnaniensia, 3(1987), s. 73-81.

67. [współautor: J. Wierzbicki] Poganice, gm. Potęgowo, woj. słupskie. Stanowisko 4. Informator Archeologiczny, Badania 1987, s. 39.

\section{0}

68. Społeczności strefy południowo-zachodniobattyckiej $w$ dobie neolityzacji, Poznań: Wydawnictwo Naukowe Uniwersytetu im. Adama Mickiewicza.

69. [red.] Die Trichterbecherkultur. Neue Forschungen und Hypothesen. Material des Internationalen Symposiums Dymaczewo, 20-24 September 1988, Teil I, Poznań: Instytut Prahistorii Uniwersytetu im. Adama Mickiewicza w Poznaniu.

70. [red.] Z badań nad chronologia absolutna stanowisk neolitycznych z ziemi chetmińskiej, Toruń: Wydawnictwo Uniwersytetu Mikołaja Kopernika.

\section{1}

71. Einige Probleme des pommerschen Neolithikums vor dem Hintergrund der westlichen Ostsee-Zone. W: K. Jennbert, L. Larsson, R. Petré, B. Wyszomirska-Werbart (red.), Regions and Reflections. In Honour of Märta Strömberg, Lund: Almqvist \& Wiksell International, s. 27-33.

72. [współautor: T. Wiślański] Trichterbecherkultur im Polnischen Tiefland - die Wichtigsten Forschungsprobleme. W: D. Jankowska (red.), Die Trichterbecherkultur. Neue Forschungen und Hypothesen. Material des Internationalen Sym- 
posiums Dymaczewo, 20-24 September 1988, Teil II, Poznań: Instytut Prahistorii Uniwersytetu im. Adama Mickiewicza i Zakład Archeologii Wielkopolski IHKM PAN, s. 53-65.

73. [red.] Die Trichterbecherkultur. Neue Forschungen und Hypothesen. Material des Internationalen Symposiums Dymaczewo, 20-24 September 1988, Teil II, Poznań: Instytut Prahistorii Uniwersytetu im. Adama Mickiewicza i Zakład Archeologii Wielkopolski IHKM PAN.

\section{3}

74. Przedmowa. W: D. Jankowska, J. Wierzbicki (red.), Kopalnia surowców mineralnych kultury pucharów lejkowatych w Poganicach, woj. Stupsk, stanowisko 4 (strefa 10), Poznań: Instytut Prahistorii Uniwersytetu im. Adama Mickiewicza, s. 7-8.

75. [współredaktor: J. Wierzbicki] Kopalnia surowców mineralnych kultury pucharów lejkowatych w Poganicach, woj. Stupsk, stanowisko 4 (strefa 10), Poznań: Instytut Prahistorii Uniwersytetu im. Adama Mickiewicza.

\section{4}

76. Frühneolithische Elemente in der mittelpommerschen Łupawa-Gruppe der Trichterbecherkultur. W: J. Hoika, J. Meurers-Balke (red.), Beiträge zur frühneolithischen Trichterbecherkultur im westlichen Ostseegebiet, 1. Internationales Trichterbechersymposium in Schleswig vom 4. bis 7. März 1985, Neumünster: Wachholz Verlag, s. 137-154.

77. Umweltbedingungen der Neolithisierung im südlichen Ostseegebiet. Bodendenkmalpflege in Mecklenburg-Vorpommern, 41(1993), s. 7-18.

\section{5}

78. Settlement in the Baltic Coastal Zone in Prehistory and the Middle Ages. W: K. Rotnicki (red.), Polish Coast: Past, Present and Future, Journal of Coastal Researches, Special Issue, 22, s. 73-79.

\section{6}

79. Neolit Pomorza Zachodniego - nie rozwiązany problem badawczy. W: E. Wilgocki i in. (red.), 50 lat archeologii polskiej na Pomorzu Zachodnim, Szczecin: Stowarzyszenie Naukowe Archeologów Polskich, s. 11-25.

\section{7}

80. Megalithic Graves in the Lupawa-Group of the Funnel Beaker Culture. W: D. Król (red.), The Baltic Sea-Coast Landscapes Seminar, Session No. 1. The 
Built Environment of Coast Areas during the Stone Age. A symposium at the Centenary of Archaeological Excavations at Rzucewo (Rzucewo-Gdańsk) 4-9 October 1994, Gdańsk: Regionalny Ośrodek Studiów i Ochrony Środowiska Kulturowego, s. 208-213.

81. Preservation of Archaeological Sites (Remarks from the "Round-table" Discussion). W: D. Król (red.), The Baltic Sea-Coast Landscapes Seminar, Session No. 1. The Built Environment of Coast Areas during the Stone Age. A symposium at the Centenary of Archaeological Excavations at Rzucewo (Rzucewo-Gdańsk) 4-9 October 1994, Gdańsk: Regionalny Ośrodek Studiów i Ochrony Środowiska Kulturowego, s. 252.

82. The Funnel Beaker Culture in Pomerania. W: D. Król (red.), The Baltic SeaCoast Landscapes Seminar, Session No. 1. The Built Environment of Coast Areas during the Stone Age. A symposium at the Centenary of Archaeological Excavations at Rzucewo (Rzucewo-Gdańsk) 4-9 October 1994, Gdańsk: Regionalny Ośrodek Studiów i Ochrony Środowiska Kulturowego, s. 108-118.

\section{8}

83. Environmental Conditions during the Neolithisation of Pomerania. W: M. Zvelebil, L. Domańska, R. Dennell (red.), Harvesting the Sea, Farming the Forest: The Emergence of Neolithic Societies in the Baltic Region and Adjacent Areas, Sheffield: Sheffield Academic Press, s. 121-128.

84. Neolityczne spichrze z obszaru ziem polskich. Sborník prací Filozofické fakulty Brněnské univerzity. Řada archeologická (M), 46/2, s. 113-124.

85. Ochrona archeologicznych stanowisk pradziejowych w Wielkopolsce - problem konserwatorski. W: H. Kóčka-Krenz (red.), Archeologia wielkopolska. Osiagnięcia i problemy ochrony zabytków, Poznań: Stowarzyszenie Naukowe Archeologów Polskich, Oddział w Poznaniu, s. 27-30.

\section{9}

86. Kommentar zu: Jürgen Hoika: Archäologie, Vorgeschichte, Urgeschichte, Frühgeschichte, Geschichte. Ein Beitrag zu Begriffsgeschichte und Zeitgeist (Archäologische Informationen, 21/1, 1988, s. 51-86), Archäologische Informationen 22/1, s. 24-25.

87. Megalithik und kujawische Gräber. W: K.W. Beinhauer, G. Cooney, C.E. Guksch, S. Kus (red.), Studien zur Megalithik. Forschungsstand und ethnoarchäologische Perspektiven, Weißbach: Verlag Beier \& Beran, s. 215-226.

88. Dr hab. Pavel Koštuřik (1946-1998). Folia Praehistorica Posnaniensia, 9, s. 260-261.

89. Remarks on the Study of Consumption in the Communitives of the Late Band Pottery Culture (LPC) and the Corded Ware Culture Inhabiting Polish Territo- 
ries (A Comparative Study). W: D. Jankowska, M. Krenz-Niedbała, J. Piontek, J. Wierzbicki, Biological and Cultural Consequences of the Transition to Agriculture in Central Europe, Poznań: Instytut Antropologii UAM, s. 27-44.

90. Głos w dyskusji. W: M. Kobusiewicz, S. Kurnatowski (red.), Archeologia i prahistoria polska w ostatnim pótwieczu, Poznań: Poznańskie Towarzystwo Przyjaciół Nauk, s. 147-149.

\section{0}

91. Z badań nad osadnictwem późnowstęgowym w Wielkopolsce. Sborník prací Filozofické fakulty Brněnské univerzity. Řada archeologická (M), 48/4(1999), s. 81-101.

\section{1}

92. Elementy „leśne” w neolicie Pomorza. W: J. Czebreszuk, M. Kryvalcevič, P. Makarowicz (red.), Od neolityzacji do początków epoki brazu. Przemiany kulturowe w międzyrzeczu Odry i Dniepru między VI i II tys. przed Chr., Poznań: Wydawnictwo Poznańskie, s. 85-97.

93. Najstarsze osadnictwo neolityczne w Wielkopolsce. Pravěk, Supplementum 8 , s. 25-39.

\section{3}

94. Dr Erika Nagel (31.12.1943 - 24.07.1999). Folia Praehistorica Posnaniensia, 10-11, s. 398-400.

95. Wczesnośredniowieczne grodzisko w Łupawie na Pomorzu Środkowym. W: J. Olczak (red.), Studia z archeologii, historii i historii architektury (Archaeologia Historica Polona, 13, s. 207-220). Toruń: Wydawnictwo Uniwersytetu Mikołaja Kopernika, s. 221-230.

96. Ziemia lęborska w epoce kamienia. Biuletyn Historyczny, 23 (grudzień), s. 33-51.

\section{5}

97. O pochodzeniu pomorskich grobowców bezkomorowych kultury pucharów lejkowatych. Folia Praehistorica Posnaniensia, 13-14, s. 133-145.

98. Kazimierz Siuchniński - uczony i wychowawca. Folia Praehistorica Posnaniensia, 13-14, s. 9-13.

\section{6}

99. Ziemia nadnotecka $\mathrm{w}$ pradziejach $\mathrm{i}$ w średniowieczu. Podsumowanie. W: H. Machajewski, J. Rola (red.), Pradolina Noteci na tle pradziejowych $i$ wczesnośredniowiecznych szlaków handlowych, Poznań: Stowarzyszenie Naukowe 
Archeologów Polskich Oddział w Poznaniu i Instytut Prahistorii UAM w Poznaniu, s. 329-330.

100. [współautor: K. Pyżewicz] Materiały krzemienne ze stanowiska 4 w Rosku, gm. Wieleń. W: H. Machajewski, J. Rola (red.), Pradolina Noteci na tle pradziejowych $i$ wczesnośredniowiecznych szlaków handlowych, Poznań: Stowarzyszenie Naukowe Archeologów Polskich Oddział w Poznaniu i Instytut Prahistorii UAM w Poznaniu, s. 53-69.

101. [współautor: T. Galiński] Bolków 1. Stanowisko z końca paleolitu i początków mezolitu nad jeziorem Świdwie na Pomorzu Zachodnim. Materiały Zachodniopomorskie. Nowa Seria, 2-3/1, s. 79-176.

\section{7}

102. Miejsce nauk przyrodniczych w polskich studiach nad neolitem w latach 19391989. W: J. Lech (red.), Pół wieku z dziejów archeologii polskiej (1939-1989), Warszawa: Wydawnictwo Naukowe PWN, s. 265-276.

\section{8}

103. Paleolit i mezolit Wielkopolski. W: H. Machajewski (red.), Wielkopolska $w$ dziejach. Archeologia o regionie, Poznań: Stowarzyszenie Naukowe Archeologów Polskich, Oddział w Poznaniu, Instytut Prahistorii UAM i Muzeum Archeologiczne w Poznaniu, s. 21-30.

104. Podsumowanie. W: H. Machajewski (red.), Wielkopolska w dziejach. Archeologia o regionie, Poznań: Stowarzyszenie Naukowe Archeologów Polskich, Oddział w Poznaniu, Instytut Prahistorii UAM i Muzeum Archeologiczne w Poznaniu, s. 261-264.

\section{9}

105. Profesor dr hab. Wojciech Kóčka - wspomnienie po latach. Folia Praehistorica Posnanienisa, 15, s. 11-21.

106. Rozwój badań nad epoką kamienia na Pomorzu w ostatnim 25-leciu. W: M. Fudziński, H. Paner (red.), Aktualne problemy epoki kamienia na Pomorzu, Gdańsk: Muzeum Archeologiczne, s. 23-36.

107. Z najnowszej historii archeologii. Dr Jürgen Hoika (4 VI 1941 - 1 II 2005). Folia Praehistorica Posnanienisa, 15, s. 453-455.

\section{0}

108. W kwestii obrządku pogrzebowego KPL na ziemiach polskich - stare i nowe problemy. Sborník prací Filozofické fakulty Brněnské univerzity. Řada archeologická (M). Studia Archaeologica Brunensia, 14-15 (2009-2010), s. 263-275. 


\section{1}

109. Die Bedeutung der Warte-Netze-Route bei Kontakten mesolithischer Gesellschaften. W: J. Meurers-Balke, W. Schön (red.), Vergangene Zeiten. Liber Amicorum. Gedenkschrift für Jürgen Hoika, Bonn: Dr. Rudolf Habelt GmbH, s. 21-24.

110. Osadnictwo wczesnośredniowieczne nad Jeziorem Wojnowickim. Folia Praehistorica Posnaniensia, 16, s. 313-326.

\section{2}

111. [współautorzy: M. Makohonienko, A. Michałowski, K. Pyżewicz] Przemiany krajobrazu przyrodniczo-kulturowego północnej strefy aglomeracji poznańskiej W rejonie Strumienia Różanego - między Górą Moraską a doliną Warty. W: A.W. Brzezińska, A. Chwieduk (red), Miasto Poznań w perspektywie badań interdyscyplinarnych, Wielichowo: Tipi, s. 41-50.

\section{3}

112. Początki działalności Katedry Archeologii UAM na Pomorzu Środkowym. Akcja weryfikacji grodzisk wczesnośredniowiecznych. Folia Praehistorica Posnaniensia, 18, s. 105-118.

113. Witoldowo, stan. 1. Osadnictwo z okresu neolitu i wczesnej epoki brązu. W: W. Kaczor, M. Żółkiewski (red), Bodzia, stan. 6, Witoldowo, stan. 1, Śliwkowo, stan. 4. Archeologiczne badania ratownicze na trasie autostrady Al, w woj. kujawsko-pomorskim, Poznań: Wydawnictwo Nauka i Innowacje, s. 415-506.

114. [współautor: P. Rozbiegalski] Między Północą a Południem. Osadnictwo schyłkowopaleolityczne i mezolityczne w dolnym biegu Warty. Folia Praehistorica Posnaniensia, 17(2012), s. 139-148.

115. [współautorzy: W. Dzieduszycki, J. Żychlińska, D. Żychliński] Wielokulturowe stanowisko archeologiczne w Otorowie (nr 66) na tle osadnictwa pradziejowego i historycznego okolic Szamotuł. W: R. Pietrzak (red.), Archeologia Ziemi Szamotulskiej, t. 1, Szamotuły: Muzeum-Zamek Górków, s. 105-226.

\section{4}

116. [współautorzy: M. Bigos, P. Rozbiegalski] Materiały kultury ceramiki wstęgowej kłutej na stanowisku Święty Wojciech 7, gm. Międzyrzecz. Wielkopolskie Sprawozdania Archeologiczne, 15, s. 55-69.

Ponadto: wiele haseł do Encyklopedii Britannica i w Słowniku biograficznym historii Polski. 